Nigerian Journal of Environmental Sciences and Technology (NIJEST)

www.nijest.com

ISSN (Print): 2616-051X ｜ＩSSN (electronic): 2616-0501

Vol 3, No. 2 October 2019, pp 410 - 415

\title{
Engineering Feasibility of Building Blocks Produced from Recycled Rice Husks
}

\author{
Atikpo E. ${ }^{1, *}$, Ukala D. C. ${ }^{1}$, Agori J. E. ${ }^{1}$, Agbi G. G. ${ }^{1}$, Iwemah E. R. ${ }^{1}$, \\ Umukoro L. O. ${ }^{1}$ and Michael A. ${ }^{2}$ \\ ${ }^{1}$ Department of Civil and Environmental Engineering, Faculty of Engineering, Delta State University, Oleh \\ Campus, PMB 1, Abraka, Delta State, Nigeria \\ ${ }^{2}$ Department of Environmental Technology, Faculty of Environmental Sciences, Federal University of \\ Technology, Owerri, PMB 1526, Imo State, Nigeria \\ *Corresponding Author: eguasbridge@gmail.com, eatikpo@delsu.edu.ng
}

https://doi.org/10.36263/nijest.2019.02.0066

\begin{abstract}
Rice husks abundance in Nigeria requires the consideration of their alternate economic uses to prevent environmental pollution from the waste heaps, litter and combustion. This study focused on the determination of the feasibility of blocks made from recycled rice husks for building construction. Twenty-four absolute cubes were moulded from a mixture of fine aggregate (sand), binder (cement) and water. These were used for control experiments. Also, 144 cubes of partially replaced sand with rice husks in the steps of 10,20,30, 40, 50 and 60\% were produced and cured for 7, 12, 21 and 28 days like the absolute cubes. They were weighed and experimented for some engineering properties including compressive strength in triplicate. The average values of triplicate readings were recorded and documented. Laboratory strengths result at the $28^{\text {th }}$ day were compared with the reference strength of sandcrete block provided in the Federal Building Code to ascertain the performances of the partial sandcrete cubes. The low maximum compressive strength of $0.54 \mathrm{~N} / \mathrm{mm}^{2}$ obtained at $30 \%$ replacement and $28^{\text {th }}$ day curing showed that rice husks were not feasible for replacing fine aggregate in sandcrete blocks at the percentages tested. This strength value is far less than the minimum allowable compressive strength of $1.75 \mathrm{~N} / \mathrm{mm}^{2}$ of individual blocks provided in Federal Building Code.
\end{abstract}

Keywords: Recycling, rice husks, housing blocks and construction industry

\subsection{Introduction}

Waste heaps from rice husks generates serious environmental disturbance in areas where rice is produced, processed and the wastes are disposed. Stake holders are usually bordered about the disposal of these husks from the environment and ignore the economic benefits accruable from the wastes. Owners of rice-mills do not see economic gain in rice husks, therefore; they offer them out to free their environments from these wastes. However, Chukwudebelu et al. (2015); Opara (2006); Opeyemi and Makinde (2012); and Nicholas and Folorunsho (2012) have proven the economic and housing benefits of rice husks in the building industry through their research on recycling of rice husk in some forms, especially in the form of rice husk ash (RHA) for economic benefits in the building industry. Carter et al. (1982) worked on the incorporation of ungrounded rice husks into handmade, kiln-fired bricks. They measured properties like density, compressive strength, modules of rupture, water absorption and initial state of absorption; and then concluded that it was possible to substitute up to $50 \%$ rice husks (by volume of clay) into bricks without dropping the properties of brick outside the acceptable limits in developing countries.

Rice husks, also known as rice hulls are the hard protecting coverings of rice grains. They are byproducts of threshing paddy and constitute close to $20 \%$ of the dry mass of harvested paddy. It is made up of about 50\% cellulose, 23-35\% lignin and 15-20\% silica. These husks are economically, readily available in Nigeria. 
Research on wastes recycling for building materials production needs urgent attention because large demand has been placed on the building materials industries owning to the increase in population and rising prices resulting in shortage of building materials.

Sandcrete block commonly used in Nigeria is defined in the Federal Building Code (2006) as a homogeneous mixture of composite material made up of cement, sharp sand and water (Anosike and Oyebade, 2012) with $2.00 \mathrm{~N} / \mathrm{mm}^{2}$ (300 psi) average standard strength for blocks, and $1.75 \mathrm{~N} / \mathrm{mm}^{2}$ (250 psi) lowest strength of respective block. This strength, if achieved through research on recycling of wastes for the production of building blocks for the construction industry, will go far in saving cost and speeding up national development requiring availability of good shelters for optimal productivities of citizens.

Therefore, this work studied the suitability of rice husks for producing low cost and lightweight construction blocks for the building industry instead of the more expensive sandcrete blocks in current use. This is also in pursuit of the use of environmental friendly, low cost and lightweight materials of required standard in the building industries.

\subsection{Methodology}

\subsection{Materials}

The materials include rice husks from a rice-mill in Auchi, Edo State of Nigeria; sharp sand (fine aggregate) of $3.35 \mathrm{~mm}, 0.85 \%, 2.64$, and 2.91 sieve size, moisture content, specific gravity and coefficient of uniformity respectively; and free from loam, organic matter, clay, dirt and any chemical matter; binder - ordinary Portland cement and potable water.

\subsubsection{Production of samples}

Following the provision of the Federal Building Code (2006), cement and sand were properly mixed to ratio 1:8 to achieve an even coloured, consistency mixture. Adequate volume of water was added to ensure a mixture of adequate workability. In the same way, rice husk was introduced in different percentages $(10,20,30,40,50$ and $60 \%)$ to produce some blocks. For this, cement and rice husks were properly mixed to achieve a uniform colour. Water was added in an adequate proportion to ensure mixture workability before moulding with a mould of $100 \mathrm{~mm}$ x $100 \mathrm{~mm}$ x $100 \mathrm{~mm}$ dimension.

\subsection{Methods}

Twenty-four absolute cubes were moulded from a mixture of fine aggregate (sand), binder (cement) and water. These were used for control experiments. Also, 144 cubes of partially replaced sand with rice husks in the steps of 10,20,30, 40, 50 and 60\% were produced and cured for 7, 12, 21 and 28 days like the absolute cubes. They were weighed and experimented for some engineering properties including compressive strength in triplicate. The average values of triplicate readings were recorded and documented. Laboratory data of experimented cubes were analyzed and the compressive strengths at the $28^{\text {th }}$ day were compared with the reference strength of sandcrete block provided in the Federal Building Code (2006) to ascertain the performances of the partial sandcrete cubes.

\subsection{Results and Discussion}

The compressive strengths results are displayed in Figures 1 and 2. Figure 1 centred on control cubes' strengths variation with curing ages. Figure 2 centred on the comparison of the compressive strengths of cubes with partial rice husks and that of the control cube at curing age 7 days. This comparison was significant to determine the relationship between strengths of partial sandcrete cubes with the 7 days' strength of control cubes. This showed a great increase in strength of the control cubes over the partial sandcrete cubes.

There was an increase in compressive strength with age, but a decrease in strength with increase in percentage of rice husks from 10 to $20 \%$, and a rise from this point to a peak strength at the replacement of $30 \%$, before a final decrease in strength with replacement of sand in the cubes. Cubes from rice husks attained a maximum strength of $0.54 \mathrm{~N} / \mathrm{mm}^{2}$ at a percentage replacement of 30 on the 
$28^{\text {th }}$ curing day. This strength was found to be far less than the minimum strength of $1.75 \mathrm{~N} / \mathrm{mm}^{2}$ specified for sancrete blocks in (Federal Building Code, 2006).

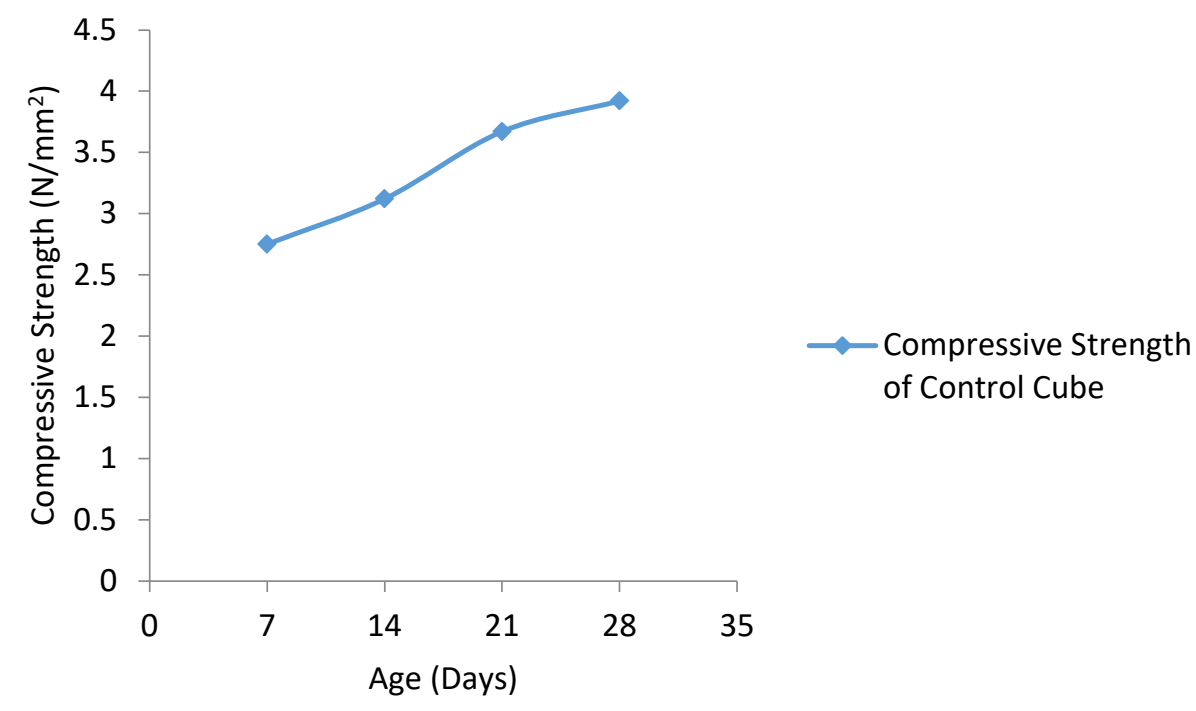

Figure 1: Compressive strength of control cube and cube age

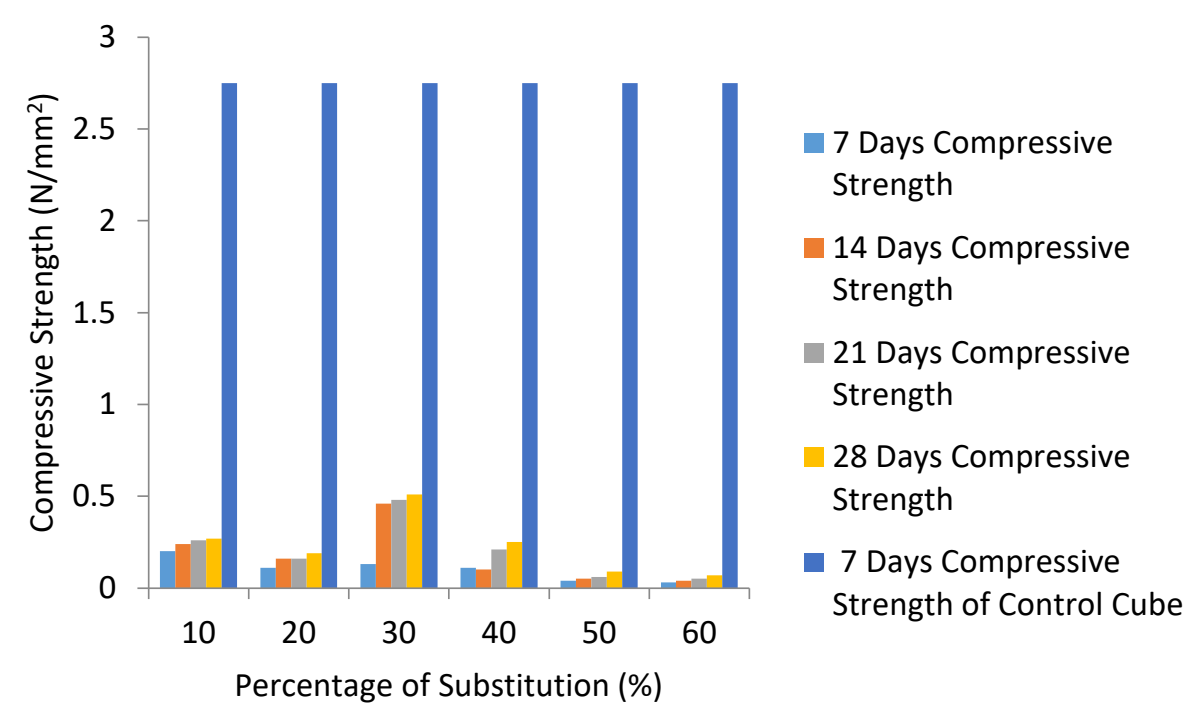

Figure 2: Compressive strengths in comparison

As shown in Figure 3, absolute sandcrete absorbed less water in comparison with partial sandcrete of replaced sand with rice husks. The water absorption rate increased with percentage replacement with rice husks. As discovered in previous work by Subramani and Ravi (2015), the more water absorption capacity of a sancrete block, the weaker the block and vice versa. The bond between blocks and mortar is highly dependent on their water absorption capacities. Thus, if the water absorption rate of a block is high; it absorbs water from fresh laid mortar and this ultimately results to weak strength (Subramani and Ravi, 2015).

A good number of the cubes produced from partially replaced sand with rice husks had higher water absorption capacities above the minimum 12\% specified in Federal Building Code (2006). 


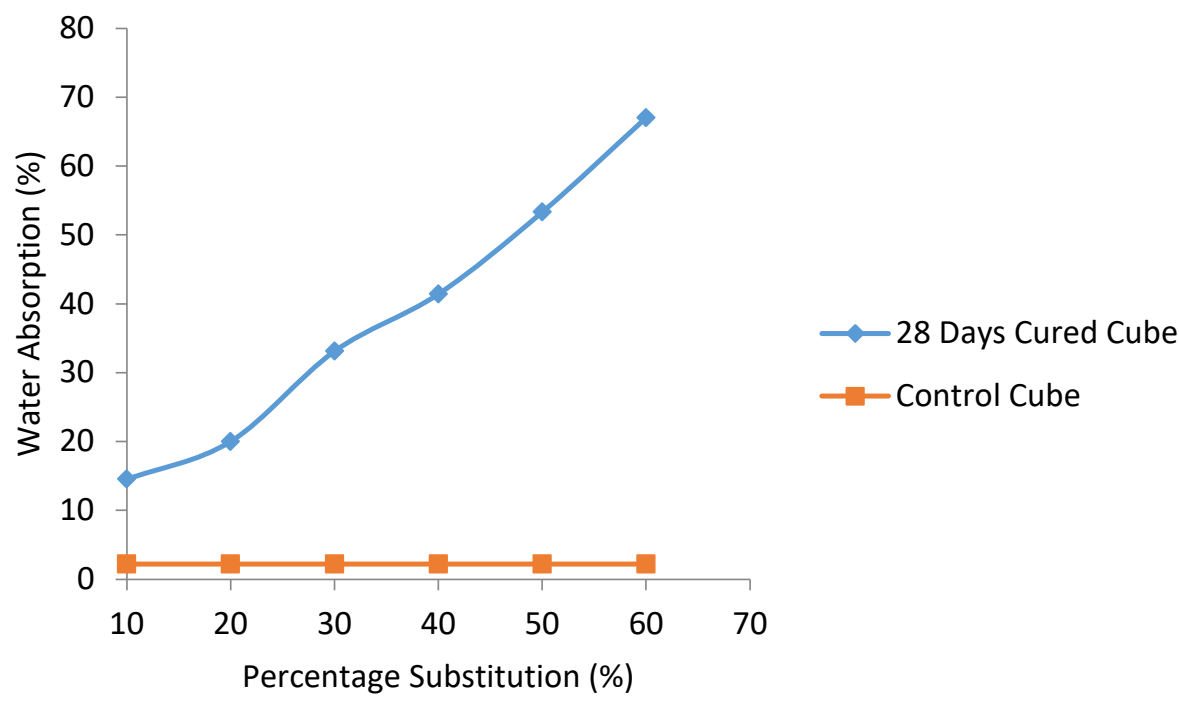

Figure 3: Water absorption capacities

Bulk densities of cubes are displayed in Figures 4 and 5. Figure 5 shows control cubes bulk densities variations with curing age, while Figure 4 centred on bulk densities comparison. This comparison centred on the bulk densities of cubes from partial rice husks at various substitution percentages with bulk density of the control cube at the $7^{\text {th }}$ day curing age. It was necessary because of the very high strength values of control cubes relative to the cubes with percentage rice husks.

The bulk densities of control sandcrete cubes were far greater than those of cubes produced from partial replacement of sand, and decreased with curing age. The bulk densities of absolute sandcrete cube at day 7 was $1992 \mathrm{~kg} / \mathrm{m}^{3}$ while that of cube from partial replacement at $10 \%$ and 14 days curing age was $1512 \mathrm{~kg} / \mathrm{m}^{3}$ as the highest values for partial sandcrete. Bulk densities were found to decrease with increase in percentage replacement of sand with rice husks. The control sample went above the minimum of $1500 \mathrm{~kg} / \mathrm{m}^{3}$ in (British Standard Institute - BSI, 2002), and also, cubes from $10 \%$ of rice husks replacement at curing ages 7 and 14 days were above the minimum requirement bulk density values of $1500 \mathrm{~kg} / \mathrm{m}^{3}$.

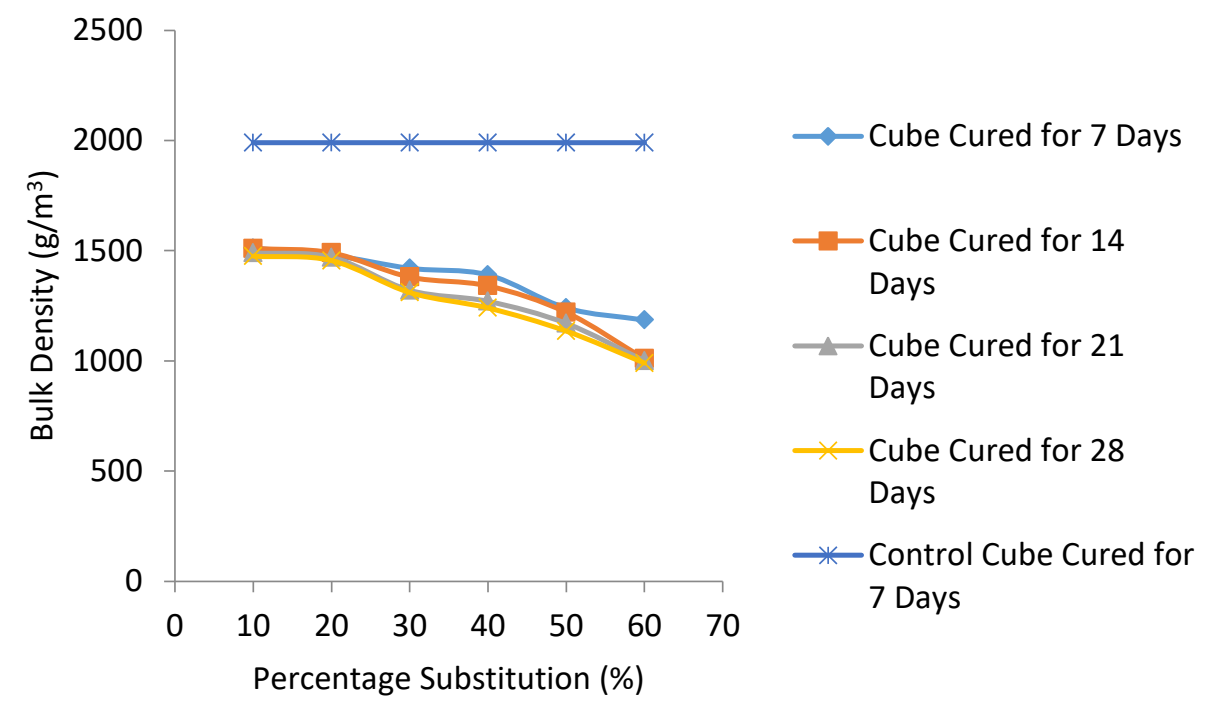

Figure 4: Bulk densities of partial sandcrete cubes and 7 days control cube 


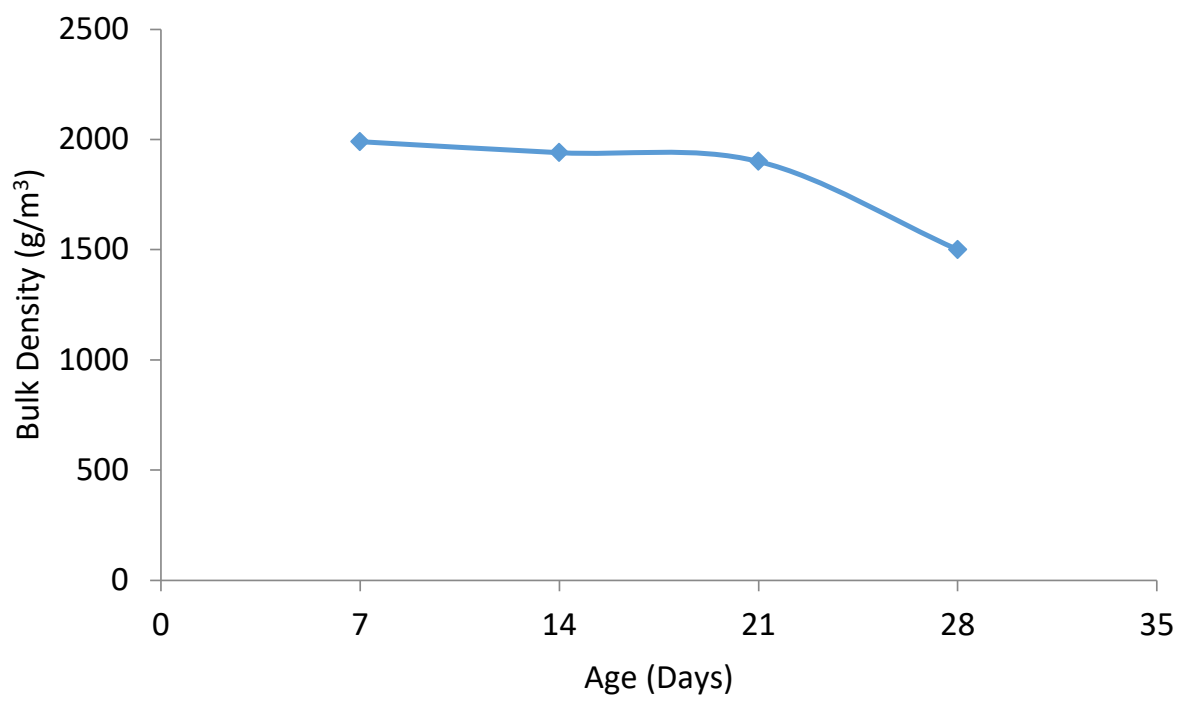

Figure 5: Bulk density of control sample with age

\subsection{Conclusions}

This work showed that rice husks were not feasible for replacing sand in sandcrete blocks at the percentages of substitution studied. This became obvious from the very low maximum compressive strength value of $0.54 \mathrm{~N} / \mathrm{mm}^{2}$ for blocks with rice husks. This value is far below the minimum acceptable compressive strength of $1.75 \mathrm{~N} / \mathrm{mm}^{2}$ for individual blocks provided in Federal Building Code (2006); and occurred at $30 \%$ replacement and $28^{\text {th }}$ day curing age.

More litres of water were required for mixing partial sandcrete than required for mixing control sandcrete. Partial sandcrete required more binder (cement) than the control sandcrete.

\section{References}

Anosike, M.N. and Oyebade, A.A., (2012). Sandcrete Blocks and Quality Management in Nigeria Building Industry. J. Engin.Proj. Prod. Manag., 2(1), pp. 37-46

British Standard Institute (BSI), (2002). Specification for Clay Bricks and Blocks, BS1200, London.

Carter, G.W., Cannor, A. M. and Mansell, D, S., (1982). Properties of Bricks in Incorporating Unground Rice Husks. Buildi. Envi., 17(4), pp. 285-291.

Chukwudebelu, J.A., Igwe, C.C. and Madukasi, E.I., (2015). prospect of using Whole Rice Husk for the Production of Dense and Hollow Bricks. Afri. J. Envi. Sci. Tech., 9(5), pp. 493-501.

Federal Building Code (2006) in Parameters for Good Site Concrete Production Management Practice in Nigeria, PhD Thesis by Anosike, M.N., (2011) and Submitted to the Department of Civil Engineering, Covenant |University, Ota, Nigeria.

Nicholas, A.M. and Folorunsho, O.A., (2012). Ultilizing Rice Husk Briquettes in Fringe Crucible Furnance for Low Temperature Melting Metals in Nigeria. ETASR. Engin. Technol. Appli. Sci., 2(4), pp. 26-268.

Opara, P.N., (2006). Usability of Rice Husk in the Production of Roofing Sheets. J. Agric. Soc. Res.,6(1), pp. $76-79$.

Opeyemi, D.A. and Makinde, O.O., (2012). The Suitability of Partial Replacement of Cement with Rice Husk Ash and Bone Powder in Concrete Structures. Inter. J. Emerging Technol. Adv. Eng., 2(9), pp. 261- 265. 
Subramani, T. and Ravi, G. (2015), Experimental Investigation of Coarse Aggregate with Steel Slag in Concrete, 5(5), pp. 64-67.

Cite this article as:

Atikpo E., Ukala D. C., Agori J. E., Agbi, G. G., Iwemah E. R., Umukoro L. O. and Michael A., 2019. Engineering Feasibility of Building Blocks Produced from Recycled Rice Husks. Nigerian Journal of Environmental Sciences and Technology, 3(2), pp. 410-415. https://doi.org/10.36263/nijest.2019.02.0066 